\title{
“Arseing around was Fun!" - Humor as a Resource in Design and Making
}

\author{
Netta Iivari \\ INTERACT Research \\ Unit, University of \\ Oulu, Finland \\ netta.iivari@oulu.fi marianne.kinnula@oulu.fi
}

\author{
Leena Kuure \\ Research Unit for
}

Tiina Keisanen

Research Unit for

Languages and Literature, Languages and Literature, University of Oulu, Finland University of Oulu, Finland leena.kuure@oulu.fi tiina.keisanen@oulu.fi

\begin{abstract}
Humor is an inevitable part of human life. Most of us are capable of experiencing and appreciating humor. From this perspective, surprisingly little HCI research can be found scrutinizing the existence, role, and potential of humor in our design practice. The gap remains also related to children and teenagers; there is a lack of studies appreciating the emergence and existence of humor in the design process without intentionally evoking it. Thus, this study examines humor as a naturally occurring phenomenon in the design process. The study was conducted in collaboration with a class of teenagers and their teachers. The study identifies various forms and functions of humor in the design process and reveals its situated, emergent nature as a resource in interaction within design. The study proposes a practical tool for designers for anticipating and potentially facilitating the emergence, forms and usages of humor as an interactional resource in design.
\end{abstract}

\section{Author Keywords \\ Making in education; Design; Humor; Children; Teenager; Interaction; Discourse; Nexus Analysis}

\section{CSS Concepts}

- Human-centered computing $\rightarrow$ Interaction design $\rightarrow$ Empirical studies in interaction design.

\section{INTRODUCTION}

Humor is an inevitable part of human life. Most of us are capable of experiencing and appreciating humor. We smile, laugh, and become amused. Moreover, humor is not limited to the confines of hobbies and leisure, but it also emerges and prospers at work. From this perspective, surprisingly little research on Human Computer Interaction (HCI) is available on the existence, role and potential of humor in our design practice, the context of this study.

Humor is a topic studied widely among different disciplines, most notably within psychology, but also within human and social sciences (see e.g. $[40,43])$. The wide range of theories

CC)
This work is licensed under a Creative Commons Attribution-NoDerivs
International 4.0 License.
CHI '20, April 25-30, 2020, Honolulu, HI, USA
(C) 2020 Copyright is held by the owner/author(s).
ACM ISBN $978-1-4503-6708-0 / 20 / 04$.
https://doi.org/10.1145/3313831.3376169

on humor and its functions available (see e.g. [40, 43]) provides evidence for the complexity of the concept. Some attention to humor has also emerged in research on computing and digital technology: humor has been shown to be relevant in relation to various kinds of technological solutions such as social media, robots, games, and interactive agents (e.g. [8, 9, 31, 32, 37, 42, 50, 59]). Humor has already been examined in the design context, too: humor has been linked to increasing creativity in a design process (e.g. [23, 36 and it has been intentionally integrated into design activities [19, 22, 23]. Principles for the design of humorous products have also been generated (e.g. [11, 63]). However, so far there is a lack of studies appreciating the emergence and existence of humor in the design process without an intentional effort of evoking it. This study examines humor as a naturally occurring phenomenon in the design process, without intentionally introducing it into the process.

Humor is not only confined to the world of adults, quite the opposite. We can understand and appreciate humor in early childhood already and humor may have a positive impact for the development of one's self-concept and learning (see, e.g., [57]). Hence, it is no surprise that studies in computing context have pinpointed the significance of humor in children's lives: in education, collaborative activities, and design activities (e.g. [4, 33, 53]). Along these lines, humorrelated design activities have also been developed and humorous design outcomes have been identified (e.g. [7, 17, 19]). However, related to children and teenagers as well, there is a lack of studies appreciating the emergence and existence of humor as a naturally occurring phenomenon in design process. This paper fills in this gap.

The study was conducted in collaboration with a local school: with a class of teenagers and their teachers interested in innovation, design and Making education. Teenagers are a specific group of research and design participants in many respects, acknowledged already by HCI research (e.g. [10, 34, 52]): they are positioned somewhere between children and adults, experiencing a significant transformation, continuously engaging in identity considerations, wishing to be seen as 'cool.' The study includes a semester-long design and Making project in which the teenagers envisioned and designed smart products that they party implemented in the University Fab Lab. Hence, this study connects with the recent hype of design and Making in education in the 
research community (e.g. [28, 29]). This paper explores the role of humor as a particular aspect in such an endeavor, asking as its research question, "How is humor used as a resource in interaction in the design process - what roles does it play, what functions does it serve?"

The paper is structured as follows. The next section introduces related research and the theoretical lens on humor in more depth. The third section presents the research design, while section four outlines the empirical findings. Final sections discuss the results and their implications.

\section{THEORETICAL FRAMING}

This section reviews research on humor for the purpose of developing the theoretical lens for this research as well as for revealing the state of the art in the computing field.

\section{Related research}

In research on computing and digital technology, there are strands of research examining humor. Numerous studies have considered humor in games (e.g. [9, 31]) and during gameplay [33, 62]. In addition, humor has been considered in relation to human computer interaction as in the case of human-robot interaction $[42,59]$ or in interaction with virtual agents $[32,37]$. There is evidence provided for humor in computer mediated human-human interaction as well: humor has been shown to picture in chats $[21,61]$ and in social media $[8,50]$. The importance of humor in computing education $[4,35]$ has even been discussed. More technical research has focused on developing means for humor recognition (e.g. [5, 64]).

Humor has been examined in the design context, too: it has been regarded as a resource and strategy in design process [1, $7,17,18,25]$ and in design reviews [56], increasing creativity of design participants $[23,36]$. Humor has been intentionally integrated into design activities $[19,22,23]$ and even principles for the design of humorous products have been proposed (e.g. [11, 63]). Some of these studies have already been conducted with children. Researchers have examined how humor pictures in gameplay [33], in social media [2], or in children's playful practices [53]. Studies have also proposed how humor can be integrated into children's design activities [19] and how humor can contribute to children's computing education [4]. Closest to our study come studies that show how humor pictures in children's creations produced during their design activities $[7,17,38]$.

However, previous studies have mostly addressed intentional use of humor in the design process rather than observed its functions and roles in naturally occurring situations. This is where this study gives its contribution to the field. Even if some studies have already examined humor as a naturally occurring, central human phenomenon, in the design context there is a lack of research inquiring and appreciating humor as a natural, inevitable part of human activity, including design activity. Until now, studies with children have only shown how humor emerges in the creations of participants [7,
17, 38], while this study shows how it is inherently intermingled with the design process. In particular, the focus is on the emergence and usages of humor in a design and Making project with teenagers.

\section{Categorizing humor}

Different theories on humor and its functions have been proposed in the literature (e.g. [40, 43]). Three main theories have been identified [43]. The first of these, the relief theory, emphasizes release of tension or stress through humor. The incongruity theory underscores the aspects of surprise, unexpectedness, oddness and violation of what is expected. The superiority theory, finally, pinpoints the importance of the sense of victory or triumph that can be associated with humor connected to laughing at others [43].

Various kinds of categorizations have also been proposed, e.g., whether humor is directed at self or others and whether it is benign or detrimental. Benign, tolerant, benevolent and non-detrimental humor can be used to protect the self or a larger collective. Humor can also be detrimental or injurious, even aggressive, towards the self or the others. Based on these distinctions, humor can be categorized as selfenhancing, affiliative, aggressive or self-defeating: selfenhancing and affiliative humor are benign forms of humor whereas aggressive and self-defeating are detrimental forms - targeted towards the self or the others. Self-enhancing humor is more directed towards enhancing the well-being of the self, whereas affiliative towards the well-being of a collective in the sense of enhancing mutual relationships and interpersonal cohesiveness as well as to reduce interpersonal conflicts. Aggressive humor aims at enhancing the self at the expense of others, while self-defeating humor aims at enhancing relationships at the expense of the self. [40]

Humor can also be categorized based on whether the aim is to unite people (identification and clarification) or divide people (enforcement and differentiation): For identification, humor is used to identify with the audience, to reduce tension, and to build group cohesiveness, while differentiation entails contrasting oneself with certain others, and ridiculing and criticizing them. Clarification and enforcement usages both relate to social norms and rules, and to what is socially expected. Clarification does not entail correction or censure, while enforcement involves criticism, ridicule, and discipline towards those deviating from the norms or from what is socially expected. [43]

\section{The situated perspective on humor}

Categorizing and labelling types and functions of humor in given data provides the researcher one perspective to the phenomenon under scrutiny. The reverse approach puts emphasis on the social actor's perspective in interpreting the use of humor as a resource in interaction - interpreted by the researcher through unmotivated examination of the data (see [12]). This study combines these perspectives due to its methodological standpoint of nexus analysis, which examines social action being accomplished in situ but also considers the discourses from diverse timespaces circulating 
that moment, reaching from the past, through the present, to the future [54].

Social action can according to Scollon and Scollon [54] be seen to take place as an intersection or nexus of three kinds of cycles. The first of these is the interaction order or social configurations between participants (orig. $[15,16])$. It addresses social interaction among people and how it is constituted - it is acknowledged that we behave differently depending on who we are with $[54,55]$. In our study, for example, the significance of the interaction order shows in the various social configurations that have been forming and evolving during a longer timespan among these pupils and teachers as well as in how adults unfamiliar to the pupils entering the classroom may change these configurations.

The second cycle, coined from Nishida [46], emerges from the historical body, i.e., the aggregation of practices or repeated experiences of the social actor in the course of life [55]. The notion of historical body aims to make visible how people's personal experiences and accumulated life histories shape their behavior [54, 55]. In our study, the relevance of historical body may show, for example, in how the design or Making related knowledge, skills and experience of the design participants, be they adults or children, shape their behavior in the project.

The third cycle, discourses in place, refers to the range of discourses that circulate more or less rapidly through the material sites where the action is taking place [54]. Material spaces are interpreted and continuously (re)constructed among participants co-present locally but at the same time as aggregates of spatially and temporally more distant discourses [54]. Participants may distribute their attention across physical and virtual spaces in technology-rich environments [30]. This study focuses on what can be characterized as a local space [49], the school classroom where the design work among the school pupils takes place. In the context of school, the architecture of the building and design of objects derive from actors spatially and temporally more distant. Voices of educational policies, pedagogic thinking and technology development of the time contribute to the shaping of the learning space, setting the premises for what kind of action it allows and hinders. On the other hand, participants can use their agency to resist those discourses and co-create new discourses as well.

The classroom as a space may even be perceived as a genre [39]. Entering a room, people have their expectations about what can be done there and the room also has its affordances for social action. Institutional spaces may also become safe spaces for participants from the point of view of their identity work as they diminish the need for justifying one's presence [60]. This suggests a balanced interaction order between participants. Room spaces can also be viewed as stages where pupils construct and perform identity through diverse performances and social games [14]. As for the present study, it is likely that the panopticon event with its particular interaction order is for all the participants the most familiar type of pedagogic arrangement in the classroom, merged in their historical bodies [54]. In such an interactional configuration, the teacher functions as a hub for communication, controls the turn-taking and the presence and absence of pupils and guests, thus maintaining ownership for the space. [54]

When exploring humor from the situated perspective, some basic aspects of human development and interaction especially in relation to young people in the context of our study, the school, need attention. The delicate skill of humor develops across childhood and youth, serving at the threshold of adolescence for forming and maintaining friendships and romantic relationships, and experimenting with new roles more broadly [57, 58]. Humor may occur with or without overt signs such as laughter $[13,27]$. Often a joke is acknowledged as a joke by participants by laughter although laughter has other functions in interaction as well. Humor is a resource in all kinds of interactions and its means are multimodal, e.g., gaze, gesture, posture, body movement, proxemics and intonation, to name a few $[47,48]$.

There are also forms of humor that appear unfriendly but may be used, in fact, to strengthen social bonds of friendship, e.g., banter accomplished through jocular mockery and jocular abuse which display "not taking yourself too seriously" [24]. However, humor is often used as a resource for teasing and bullying as well, and the borderline may be elusive [44]. Teasing challenges the target identity, instrumental goals, or relationships between participants by invoking alternative interpretations of the content; the ambiguity produced by contrasting forces is elucidated in the interaction between the participants to achieve balance. In bullying, the balance is not achieved [44].

Much of the humor and play among participants contributes to the reciprocal process of impression management [14]. Identity work is done through the social positioning of self and other operating on multiple levels simultaneously $[3,6]$. In a classroom context, one domain that may invite identity work through humor is that of expertise, e.g., how proficient or knowledgeable pupils are positioned either by themselves or by others [41]. Moreover, it is not only the social relationships within the classroom space that are visible for the researcher. Interactions in situ may also reveal some of the relationships and identity work in communities reaching beyond the classroom.

\section{RESEARCH DESIGN}

This section introduces the context, research lens, and procedures of data collection and analysis of this study.

\section{Context for the study}

Our research group has organized projects with local Finnish schools for over ten years, with the intention to familiarize children with skills in digital technology design and Making, and to find ways to integrate this type of working in the school curriculum. This time, the data for this study were collected in a design and Making project with a class of $9^{\text {th }}$ 
graders ( 23 pupils, 15 girls, 8 boys, $14-15$ years of age). The project was carried out in connection with a multidisciplinary learning module, which was established as a compulsory element of each school year in the new national curriculum [45]. The school themes involved were English (as a foreign language), entrepreneurship as well as arts and crafts. The project followed course sessions where the pupils had been ideating concepts for their possible future business purposes. During the project, all the pupils from one class took part in design and Making workshops. The project group consisted of four Master's students from Information Systems/HumanComputer Interaction and one from English Studies. They conducted the practical work at school in the role of junior researchers. Four senior researchers guided their work and helped them in designing the sessions with children.

\section{Data collection and analysis}

The project followed the Ethics guidelines and criteria of the Finnish National Agency for Research Integrity. Informed consent was asked both from the guardians and study participants. Our research draws on the notion of mediated discourse and nexus analysis as its methodological arm [55].

The data for this study includes answers to a background questionnaire, video recordings from four workshops (product ideation; design and implementation in the University Fab Lab; preparing a presentation; presenting the design process and final product to the whole class), pupil interviews, project management data, results reports, and field notes of one senior researcher. From the point of view of this analysis, the most significant data is the video data from the different sessions. The participants in the school classroom included not only the pupils but the project group of junior researchers, the senior researcher, and teachers (all anonymized in this study). This was the case also in the Fab Lab sessions where, however, there were also a range of other people in the same space, not involved in the project activities (e.g., visitors with their hosts getting acquainted with the Fab Lab, students at work on the computers, occasional individual school pupils, and lab instructors).

The data analysis process in this study proceeded as follows. Firstly, data logs were created from each video recording (e.g., participants, basic features of the event and data file, and some rough transcription of the interactions). Next, the researchers viewed the video recordings individually and together several times making notes and discussing their interpretations. The field notes with observations from the events were also utilized. The research focus was delineated on the basis of these viewings and discussions to the use of humor as a resource in the design and Making project. In the initial phase, the researchers saw the activities in the classroom as primarily fun-making, or "arseing around" as a pupil later on evaluated their work. However, a closer examination of the materials started to bring into light the multifaceted nature of the activities and the more "serious" work with the design concepts and products. In the following phase, the video recordings were viewed again, identifying in the data moments that involved humor related to the design and Making process in particular. Transcriptions were made according to the needs of the analysis. The theories and functions of humor were used as sensitizing devices during initial data analysis. For more in-depth analysis, the triad of social action (interaction order, historical bodies, discourses in place) was used as a theoretical lens [54,55].

\section{EMPIRICAL FINDINGS}

In the following, we will present findings from our data analysis. The steps in the design and Making project are discussed chronologically. We examine humor related to the design process both from the researcher and the participant perspective. Humor is viewed as an interactional resource that is identified either 1) in the participants acknowledging something as humorous (e.g., through laughter or by participating in the multimodal co-construction of a playful event), or 2) in the researchers identifying aspects related to more distant discourses shared between all or some of the pupils (e.g., current topics at school or the media).

The main focus will be on the advancement of design work in the so-called Specs team whose design concept was spectacles with led lights. The team consisted of two boys, Teppo and Matti, and two girls, Hanna and Anni. The team is approached, however, in relation to a whole range of other participants in the sessions.

The data transcripts below do not do justice to all the delicate multimodal aspects of humor in situ, but we will try to illustrate the situations as carefully as possible in text. The original Finnish talk has been translated to English by the authors. Some of the discussions were originally in English as the design and Making project was also related to pupils' English teaching. All names are pseudonyms. The full stop within brackets refers to a short pause.

\section{Establishing first contacts with the pupils}

The project group made first contacts with the ninth-graders through a short introduction to the design and Making project at the beginning of an earlier class session. In the written answers to the background questionnaires, some signs of humor can already be identified: the pupils were using informal expressions, which could be interpreted as attempts to establish identification and affiliation with the project group through humor, e.g., $k y l$, $k h y l$ or $j u u$, all colloquial Finnish alternatives for 'yes'. The answers imply a relatively informal interactional atmosphere and power configurations between the pupils and their teachers on the whole.

\section{Design workshop}

On the basis of data analysis, four subsequent phases could be discerned in the design workshop at the school. These were 1) getting organized, 2) negotiating competence and meaningfulness, 3) evaluating ideas, and 4) presenting the idea. Findings in relation to the forms and functions of humor are presented as regards each phase. As for the school setting, it was a familiar place for all the participants, although due to their different ages, the school and learning culture may have 
had different emphases in terms of power configurations and working methods. The design and Making project was a novel approach for everyone involved.

\section{Getting organized}

Starting from the situated perspective, stretches of interaction chosen from the video recordings are analyzed in more detail. In getting organized, humor emerged as a resource for creating a good atmosphere conducive for collaborative design work. The first video extract shows how the project group and the pupils have gathered together in a classroom at the school to start the design and Making project. The situation is organized as a panopticon event, where the pupils are sitting in the traditional arrangement in the classroom (at their desks, facing the front), although they have placed themselves together with their team members already. The pupils are chatting with each other, when Lassi, one of the junior researchers, begins the design session. However, he has barely done so, when one of the members in the Specs team, Matti, says in a rather loud voice, 'there is nothing sexual'. This comment is directed at a girl in another group, who has noticed that Matti is holding his hand around Teppo. She has raised her eyebrows and made faces at Matti, which instigates the comment from Matti. Matti's turn draws everyone's attention in the room. Most pupils turn to look at Matti and Teppo and many laugh and smile. Matti himself laughs audibly for a lengthy period afterwards. These are indications of the laughable nature of Matti's actions. Yet, there is other interactional work being done at the same time: as the junior researchers and the pupils do not know each other from before, there is a need for establishing the interaction order for this class session and for the design work that follows. Humor seems to work well here as a resource as Lassi continues Matti's jocular tone by responding 'let's keep hands in our own pants'. Further, the mention of 'nothing sexual' points towards the identity work that the teenagers of this age are engaged in. This indicates that participants' experiences - their historical bodies - are involved in every action. On the other hand, in terms of the design and Making project, the close relationship between Matti and Teppo becomes evident. Their work as team members can rely on their familiarity with each other.

The starting of the design session is also the first session, which will be video recorded for research purposes. The junior researchers take care of some of the practicalities involved in this at the beginning of the class, including handing out and collecting the forms for informed consent. Securing consent is a delicate task, since participation in research is voluntary, and therefore needs to be negotiated with each potential participant. One of the pupils, Hanna, has been filling the form, and when ready, hands it to Lassi. Lassi inspects the form, but as becomes evident from his turn that follows, Hanna has not written down her name on the form. His request 'uhum it helps considerably if you have the pupil's name here' is formulated indirectly, as a statement. Hanna laughs when she receives the form and writes her name on it. Her laughter is a sign of the delicate nature of the activity, and it also acknowledges her oversight (see [20]). Participation in research is a rare activity in anyone's life, and in such occasions, the unfamiliarity of the process and the expectations of how to act may be mitigated via humor.

There are multiple interaction orders being maintained and under construction in the beginning phases of the design sessions, e.g., the relationship configuration within the team, within class as an interplay between classmates, and in relation to project work led by the project team. Humor and laughter have a central role here. Humorous exchanges and actions strengthen the group dynamics in the whole class, not just within the teams or between the project group members and the pupils. They reflect and build up an interaction order that involves close, balanced relationships between participants, which again, serves to create a fruitful basis for the collaboration required in design work.

As for the historical bodies of the participants, spontaneous interaction and mutual joking and laughter are "normal" behavior in the Finnish school class, also between the pupils and the teacher, and thus also part of the accustomed practices of the ninth-graders beyond this project. The topics of the witty repartee are typical in the interactions of this particular age-group of teenagers and teachers do not usually interfere with it unless it becomes a disturbing factor for learning or bends agreed ethical standards.

The examples above show how joking, laughter and wordplay build up a light atmosphere with humor, providing affordances for relieving tension and building cohesion among different groupings of participants co-present. This serves in establishing a balanced interaction order between the project group and pupils.

\section{Negotiating competence and meaningfulness}

In the first phases of the first session with the class, the project group is distributing pupils' draft concepts for design that they have been brainstorming in an earlier session of the multidisciplinary learning module. While the concept papers are being delivered to their owners, Lassi offers an "Apple" concept that Matti from the Specs team, however, rejects saying 'no'. The concept does, however, belong to the team and they take it from Lassi. Self-deprecating comments such as "I'm bad at maths" have been shown to prefer disagreements along the lines "No you're not" in response (see [51]), and this is the flavor of Matti's comment 'this is yh ih, it makes one sick', which he produces once the paper with the Apple concept is in front of him. Matti downplays the group's earlier idea, but he does this with a smile on his face. Many pupils laugh in response, as do the project group members. Significantly, the turn is responded to by a pupil in another group, who goes on to downplay their group's concept as well. From another perspective, we can see Matti's humorous turn to contribute to group cohesion (see [26]) in that his jokingly produced negative evaluation opens up the floor for the negotiations of appropriateness and suitability of their ideas for further work, or in other words, their competence that is required for stepping forward in the 
design process.

Considering interaction order, the project group members are not regulars in the classroom and their presence demands some impression management and facework from the pupils as Matti's interactions during concept delivery and acceptance also show.

What appears as a recurring issue to deal with is the meaningfulness of design as a "real-world task" of interest in contrast with a "school task". The pupils engage in constant humorous (verbal) play with the junior researchers about whatever is being done, about what they agree to take on as a task. The pupils also inquire if their work is assessed, whether they get a grade or not. Matti asks, 'does this affect anything at all, that this is totally über shittiest, does it have an impact on anything'. It is difficult for the pupils to perceive what is expected as the design and Making project represents an approach to school work different from normal. The project is a new working method not only for the pupils but for everybody. Therefore, there is constant negotiation about the work throughout the process.

These examples show how humor can be used in facework throughout the design process in establishing, maintaining and putting to test mutual relationships among participants. At the same time, it was used in negotiating required competence in the design task. Furthermore, humor intertwined with interactions related to the pupils' sensemaking about whether the design task should be treated as a school task or something else.

\section{Evaluating ideas}

An essential phase in the design process is evaluating ideas presented and making decisions about which of the ideas to take forward. Different ways of legitimation are presented for a workable idea. After the brainstorming has been going on already for a while, and the teams are getting closer to choosing their favorite idea, Jonne from the project group hears what the Specs team is suggesting and says, 'yes that's a nice idea.' Lassi comes closer and takes a photo. There is some inaudible chatting and Matti then says, 'I don't think it matters it's actually quite fun doing planning all in sweat here'. When the project group has given both verbal and actional confirmation (photo) about the success of the idea Matti admits that the activity is sensible. The brainstorming and planning advances, the participants joking and engaging in verbal and multimodal play, but they nevertheless work on topic as well at times being able to get their idea delineated.

Although much of the design workshop is characterized by joking and humor in many forms, and one might speculate how "serious" the pupils are in relation to the project, there is evidence of pupils valuing the new experience. Matti asks the project group, 'are the others doing the same (project).' After a negative answer he says, 'yesssss,' indicating satisfaction with the potential desirability of the project in others' eyes (this class in relation to other classes).

These examples show how humor was, once again, used for inviting legitimation for the team's design ideas, thus strengthening self-confidence in negotiating decisions about viable alternatives to develop forward in the design and Making project at hand. Humor was also used for testing the work ethos and authority between the pupils and the adults, as observed by the senior researcher.

\section{Presenting the idea}

At the end of the workshop session, the teams present the design concepts that they have arrived at. From the Specs team, Teppo steps forward and illustrates their idea that was finally delineated to be a set of spectacles with led lights. Teppo presents and the rest of the team participate with their comments. Teppo starts, drawing on the whiteboard 'the first phase, we'll draw Pete, Pete is drawn'. Hanna adds 'eyes are drawn'. Teppo continues 'they became a bit small'. Teppo continues drawing, 'there it is, that's Pete (knocking head) Pete is wearing specs but there is a trick in the specs. They are not real, they are transparent and there are like RGB leds inside. A small strip. They are directed by a remote control. Which is as big as Pete's head, hahhah. There is the remote control.' The class follows the presentation intensively. Teppo changes the role from a pupil and team member to an entertainer on stage, indicated by a change in his linguistic comportment. He produces a complete description of the item providing illustration through drawing.

As a presenter, Teppo creates a narrative involving the audience by intertwining the drawing and verbal description in short sequences. The humorous tone is created by picking an imaginary person with a colloquial nick name as a user of the product. Moving from the team discussions which were dominated by joking and playing around, Teppo changes the genre to a more serious tone even if accompanied with humorous elements. Teppo's presentation shows that the team has worked seriously as well, they have acquainted with the topic properly, perhaps not during this project, however. Teppo is also developing the idea further while describing the 'led specs' to the others as the product design becomes more concrete. The assumed audience for the presentation seems to be the other classmates. The functions of humor could here be seen as engaging and amusing the audience, strengthening affiliative bonds in the community.

To sum up, in the final phase of the design workshop, the team product was made public to the others co-present. This entailed some humorous play about the presentation of the design. This suggests facework anticipating how others will treat the team's accomplishment but also some impression management from the perspective of the presenter as well as from the perspective of the other team members accompanying the presenter's work. The participants also engaged in negotiations about their project experience in relation to other classes in the school indicating the desirability of the experience in others' eyes.

\section{Design and implementation in Fab Lab}

In this phase, the group has their idea decided upon, while they now need to make it real. For that, they still need to first 
do some more design work. Almost the entire session consists of Teppo concretizing and implementing the idea, while the other group members are engaging in unrelated discussions on various topics, having fun and joking.

There is heavy emphasis again on identification and affiliation in relation to those co-present, building group spirit through mutual topics and humor. The pupils are browsing pictures with their smart phones, laughing at each other's appearance and their own. In these instances, the humor seems to be benign and equally directed at self and others; humorous observations are presented on both. More aggressive use of humor is also observable in the comments about others not present. This could be seen as bringing forth differentiation in relation to them, but at the same time building group spirit and cohesion among those co-present. Such joking was, however, not directly relevant for the advancement of design work.

The team members again occasionally engage in belittling their own performance: 'our group is quite good (laughter) real shit ... somebody finishes something when nobody in the team can't ... we are so self-directed'. Through belittling their contribution, the team could be seen as doing facework to the direction of Teppo who is doing all the work while the rest of the team are just having fun. The concrete phase of the design process requiring drawing, measurement, and use of a computer and digital tools led to uneven workload in the team in the Fab Lab. While Teppo was doing the actual work, the others were spending time, and negotiating the value of their contribution.

Overall, in this session benign humor was observable, working towards identification and affiliation in the team but also relieving tension in front of the task at hand and unequal distribution of labor.

\section{Preparing for presenting the results}

In the session where the teams are getting prepared for presenting their results, the Specs team is missing the most active member, Teppo, for almost the entire session as he arrives during the last fifteen minutes. Nevertheless, he takes the lead in finalizing the presentation. The quality of the video of this session is quite poor and detailed observations of humor are impossible to make. Generally, the group engages again in fooling around and making fun around their design solution, including bodily choreographies as well as humorous remarks while fitting the specs on the face, as in 'a little lopsided, for Santa Claus, hehheh, just wait for a year and you'll find these in every supermarket'. The reference to the future popularity of the product could be seen as indicating a negotiation of approval of or satisfaction with the team's final product as a joint accomplishment of the group members.

\section{Presentation of the results}

When the pupils present their project results to their classmates, researchers, and teachers with PowerPoint presentations, the slideshows were again built to amuse others, showing an intention for affiliation and identification. The stylish presentation slides of the Specs team start with a movie-like theme and continue with an advertisement of the product the group produced during the project. The general feeling when watching the presentation is that it was built to amuse the audience and through that to enhance the credibility of the speakers. That showed also in how wordings of the pupils were intentionally chosen to amuse others: 'It would be über hot if ...'

Using humor for relieving tension of the presenters is also quite clear. The presenters accompany their narratives with smile and laugh at their group members' presentations (in a positive way). Some inside jokes can be identified during the presentation, e.g., when two presenters grinningly look and point at each other, sharing something that the audience is not aware of. At the end of the presentation, when the audience gives applause, two of the presenters also clap at themselves, very showingly.

\section{Post-interview}

The teams were interviewed at the end of the project. The interview again brings to the surface humor use aiming at affiliation and identification with the group. The Specs team humorously describes their work and challenges involved, engaging with the adult interviewers also in a humorous manner, asking them provocative questions and making provocative statements: 'quite a few things were difficult ... what did we even do there (laughter) difficult to make them good-looking ... good-looking hehheh ... are you claiming that they aren't ... everyone said that we should change the idea, we had that pen (laughter) ... certainly exceeded the expectations, we thought that this is not going absolutely anywhere, but at least something ... at the beginning it didn't look like it ... we completed the job, the rest of the time we were arseing around ... arseing around was fun, that's it!'

The team also makes fun of the fact that one person actually carried out most of the tasks. Matti states, 'well Teppo did most Teppo knew how'. Teppo asks, 'when I was away did you put the leds in place' and the rest of the team answers 'no, we did offer help ... everybody did something, though (laughter)'. Relief of tension can also be connected with this collaborative negotiation around the obviously unequal workload within the group. When reflecting on the past project, the team also makes fun of their various design ideas strengthening the idea of their team cohesion and the 'led specs' as a joint product of the whole team.

\section{DISCUSSION}

The aim of this paper was to examine humor as a naturally occurring phenomenon in the design process with teenagers in school context. Hence, we did not intentionally introduce humor into the process - humor was not considered in the research design and the use of humor was not tested as part of our research or design process, but it emerged as a special focus during our iterative data-driven analysis. In the further data analysis, we wanted to understand what kind of resource humor can be in interaction in the design process - what 
roles it plays and what functions it serves. We adopted a situated perspective, where the classroom space, social relationships and interactions between participants, their historical bodies, and various discourses circulating the project were used as a starting point to study the phenomenon. Next, we discuss our findings and their implications.

\section{Summary of the findings}

Our analysis illustrates how humor emerged as a resource in a design and Making project in multifarious ways. Humor emerged already the pupils' answers given in the background questionnaires and the pupils' questions and comments in the first information session implied informal relationships between participants. The humorous aspects intertwining these interactions may be seen as a normal interactional resource, ranging from expressions of bonding between peers to negotiating the nature of the task at hand with those leading the activities (i.e. the project group).

In light of the categorizations of humor discussed in the theory section, many of these resources were related to identification and affiliation with the communities in situ (e.g., among classmates, between pupils and the project group). Humor was also used for relieving tension, which was needed as design work, especially in relation to Making in the Fab Lab, was a new phenomenon for all the participants, not merged in their historical bodies as pupils, teachers or project leaders. In addition to design work, the research team was unfamiliar to the pupils prior the project, potentially increasing tension as well as work required for building mutual relationship. Despite these factors, we are not claiming there was a lot of stress or tension in this project, but in interaction in general various kinds of activities are typically accomplished in the anticipation of their emergence. Furthermore, the dynamics of teamwork always require negotiation for a balanced distribution of labor, sharing and constructing knowledge and making decisions on which of the new ideas will be furthered in the coming design. The threat posed by such steps is often mitigated through joking and laughter.

The analysis of humor during the design and Making project brought into foreground the constant interplay of multiple interaction orders as there are overlapping agendas at work in the classroom. An important part of the humorous interactions was related to the pupils maintaining and enforcing their mutual relationships and facework. Although for an outsider, the ongoing repartee, wordplay, banter, teasing and even cursing may seem unacceptable, exposing incongruity with others, such behavior must be interpreted in the situational context of its emergence. In a Finnish school, and especially for this particular group of pupils with their teachers this was rather normal, not slipping out of control or disturbing the working atmosphere for learning. It is a question of the participants' historical bodies related to what school entails, and mutual negotiation for interaction orders in a particular situated place for social action that maintains and potentially renews a shared understanding of what is appropriate conduct in a classroom.

\section{Implications of the study}

The implications of the study are particularly targeted at researchers and practitioners 1) working with teenagers or children, 2) organizing design and/or Making projects with children or teenagers, or 3) working in school context. We argue for the importance of the following: 1) supporting and facilitating benign forms of humor in the classroom for purposes such as group cohesion, stress relief, facework, and impression management; 2) approaching the classroom as a complex microcosmos that requires a careful study before engaging in practical design and Making activities; and 3) a self-reflective as well as a responsible, ethical stance towards one's own role in cultivating humor as well as towards the multifaceted nature of humor in the classroom. In addition, we propose a practical tool for designers for anticipating and potentially facilitating the emergence, forms and usages of humor as a resource in interaction.

Humor has already been identified as an important element in the design process, e.g., for increasing creativity [36], to the extent that it has become intentionally integrated into design activities [19, 22, 23]. In the light of our findings, we welcome such an approach of supporting benign humorous activities between the participants and seeing humor as a valuable resource in the design process. Even more importantly, we suggest appreciating humor as a naturally occurring resource of human interaction for building group cohesion and dynamics, stress relief, facework, and impression management, among others (see also e.g. [14, 26, 40, 41, 43]). Furthermore, when participants are facing new tasks, especially of a new kind, they need to have space and time to engage in meaning-negotiation to be able to share their goals. Without such negotiation, the participants' ownership to the project and, consequently, commitment and agency cannot grow. Humor in its multimodal manifestations is an important element here: facilitating the facework related to participants' identity-building as competent actors in activities at hand (see also e.g. [14, 26]).

When working with children in school context we encourage researchers and practitioners to understand and appreciate the classroom as a complex microcosmos: as a multifaceted constellation of people, objects, tools, relationships, discourses, as a stage with particular performances (see also e.g. $[14,39,49,54,55]$. A design project is not a spatially and temporally isolated unit. Instead, the situated perspective brings along the complex configurations of interaction orders between participants in the classroom but also beyond (e.g., friends, family, interest networks) and their historical bodies (personal histories, experiences, beliefs, customary practices). In the classroom, there are the situated here-andnow discourses circulating at a fast pace, but also more distant, slow-pace discourses may gain importance (e.g., the curriculum, school tradition, parenting, media topics). For organizers of design and Making projects, it would be 
important to delve into these aspects of everyday life at school at least to some extent to be able to anticipate and understand what may be shaping the multifaceted and multilayered interactions among pupils during the activities, especially in the case of teenagers as project participants being in a delicate transition phase from childhood towards adult age (see also e.g. [10, 34, 52]).

It is important for project organizers to remember that although humor is an inherent part of interaction and can also be considered a resource in project management, facilitators need to adopt a very self-reflective as well as responsible, ethical stance towards humor as a resource in interaction. The organizers need to be aware of the power play of interaction order in order to ensure equal participation and avoid favoring some actors at the expense of others. It should be remembered that the more quiet or reserved participants should be given a possibility to strengthen their agency as well. Although loud-voiced pupils or performers cultivating benevolent humor may have a positive impact on the overall atmosphere in class, strengthening group cohesion, the quieter participants must be given opportunities for full participation as well. It is also important to remember that humor is often used as a resource for teasing and bullying, and the boundary between these may be hard to grasp [44]. Organizers need to pay careful attention to this to prevent and discourage bullying in the classroom. Additionally, it is also important for the project organizers to explore and reflect on their own institutional positions (e.g., as teachers, students, researchers, facilitators, peers) in relation to the pupils to understand how pupils will interpret their roles, and, consequently, their doings. For adult organizers, engaging in humorous activities may be highly beneficial from the perspective of encouraging an open, relaxed atmosphere and creative design and Making activities among pupils. Nevertheless, the classroom needs to be viewed as a microcosmos, with its interaction orders established and emerging, with its complex power dynamics. Humor has a very delicate role in interaction: in relationship and impression management, in community building and cultivation. We need to respect and value it, but also remember to approach it with caution.

As for implications for design, we propose a practical tool with which a designer entering a design situation may try to anticipate and facilitate the emergence, forms and usages of humor as a resource in interaction (Figure 1). The model, based on our theoretical lens of nexus analysis with its concepts of interaction order, historical body and discourses in place (see $[54,55]$ ), contains two axes: the first concerns the degree of familiarity between the design participants (related to interaction order), while the second refers to their acquaintance with the task in question (related to historical body). In the center of the figure, some key functions of humor are brought up. They may emerge in different situations due to the relational and experiental configurations between participants with their relative experience and knowledge, embedded in discourses in place.

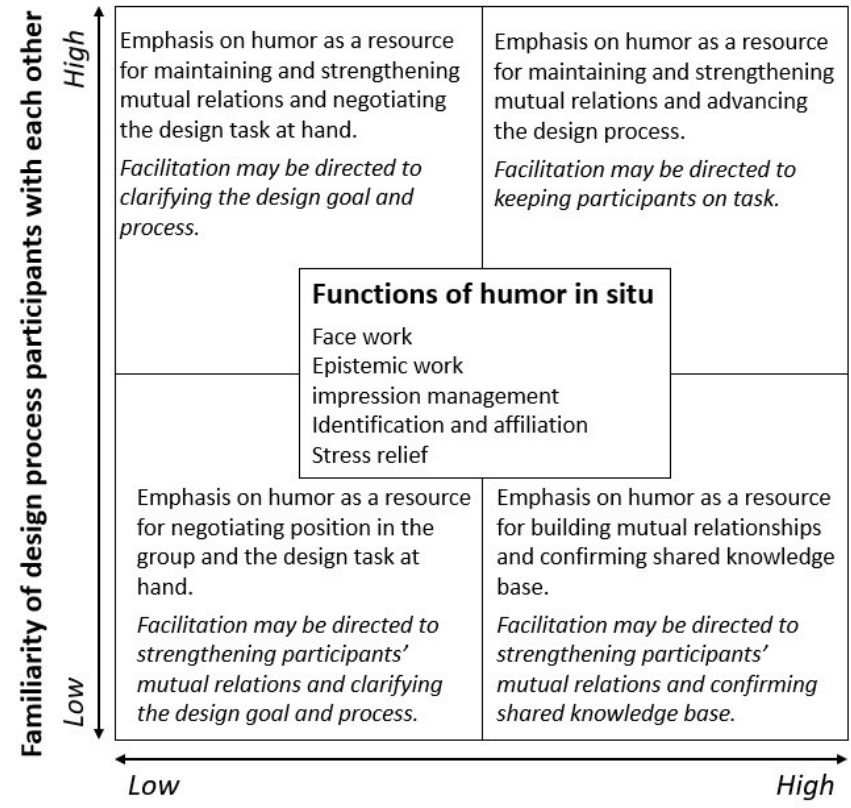

Familiarity with the design context and design process

Figure 1. Anticipating and facilitating the emergence of humor as an interactional resource within design

The axes allow us to identify four different design situations, diverging in the extent how much common ground there is among the participants and how much work is required from the participants in establishing it. The designer needs to consider the following constellations. In case both the participants and the task are familiar, humor may emerge as a resource in maintaining and strengthening already established mutual relations as less attention is needed for figuring out what the nature of the design task is. It may be useful to dissolve prevalent interaction orders to advance fruitful collaboration and on-task focus. In case both the participants and the task are unfamiliar, humor may emerge as a resource for negotiating position in the group and the design task at hand. The designer can expect the situation to be somewhat stressful for the participants and humor to emerge for its relief. Thus, support is needed for participants to build mutual relations and make sense of the design goal and process. In case either the task or the other participants are unfamiliar, humor may act as a resource in various kinds of negotiations related to mutual relationships or shared knowledge base. Support may be needed for balanced interaction order or for making sense of the task and the design process. According to the different constellations concerning familiarity with the participants and the design process at hand, humor may arise as a useful resource in doing face work and impression management to achieve identification and affiliation with the other participants, and doing epistemic work in negotiating shared ground for the design process to advance successfully. In all cases, humor may also function to alleviate stress. We remind, however, that humor is only one resource in interaction and the designer never has a full control over it. 


\section{CONCLUSION}

Surprisingly little HCI research can be found scrutinizing the existence, role and potential of humor in our design practice, approaching humor as a mundane phenomenon in human interaction. This gap also remains in research related to children and teenagers. This study examined humor as naturally occurring in the design process with teens. The study was conducted in collaboration with a local school: with a class of teenagers and their teachers interested in innovation, design and Making education. The study identified various forms and functions of humor in the design process and revealed its situated, emergent nature as a resource in interaction.

The study identified interesting implications for HCI research and design. The study emphasized the integral role of humor in all human activity, including design and Making, Humor enables addressing delicate issues, while a lot of sensitivity is needed concerning the fine line between humor and bullying. The study concluded by arguing for the importance of: 1) supporting and facilitating benign forms of humor in the classroom for purposes such as group cohesion, stress relief, facework, and impression management; 2) approaching the classroom as a complex microcosmos that requires a careful study before engaging in practical design and Making activities; and 3) a self-reflective as well as a responsible, ethical stance towards one's own role in cultivating humor and towards the multifarious nature of humor in the classroom. As a result, a practical tool for designers for anticipating and potentially facilitating the emergence, forms and usages of humor as a resource in interaction was proposed.

As for the limitations of the study, this analysis shed light on a design and Making project in a Finnish school with a particular class of teenagers. The power relationships and interaction orders that were natural in that particular environment of pedagogic culture are not generalizable to any context. These results were gained with one specific class, in which the participants were familiar with each other, but into which an unfamiliar research team entered. Our situational approach sees humor as a resource in interaction, in which there always is a complex constellation of participants involved and the emergence, forms and usages of humor depend on that. With different kind of constellation of participants, differences can be expected. We particularly point out that cultural aspects (broadly interpreted) need to be recognized, and in several senses. The participants in our study had a shared cultural background in many respects: they were pupils from one class, they knew each other and their teachers, they had quite a similar background as teenagers in Oulu, Finland. Definitely this background influences what is considered humor, the forms it takes and the roles it plays. The research team also had a shared cultural background with the study participants, while only to an extent. Even if they have children of the age and some of them also extensive experience as teachers of the age group, there for sure are many aspects of humor that remained unrecognized due to differences in terms of age and, consequently, communities and related discourses. We were able to recognize and interpret many aspects (e.g. memes, language games), while we certainly remained ignorant about others. However, this is not critical as we did not aim to comprehensively capture and classify all instances of humor but rather to understand how it functions as a resource in interaction, the strength of our analysis being in shedding light on the complexity involved. We utilized the versatile, multimodal research material and in-depth collaborative data analysis to ensure the trustworthiness of our interpretations.

Despite the limitations, we maintain that the results are valuable in other HCI contexts as well, particularly in groupwork situations. Humor is an inevitable part of human life in general and it acts as a resource in interaction among people of all kinds. With different kinds of participants in groupwork, be it related to design, making, or research on $\mathrm{HCI}$, one may expect the emergence of humor as a resource with adults and children, at work and during leisure time, with people familiar to each other as well as with strangers, in familiar everyday settings as well as in unfamiliar places and spaces. Studies exploring the topic in different cultural settings and with differing age groups are warmly welcomed. Future research is also needed to provide an even more detailed account of humor as a multimodal resource to see how the interactions unfold moment by moment in design and Making activities. Based on our results, we recommend directing special attention to the phases critical from the perspective of the emerging design concept and product.

In sum, we advocate the situated perspective on humor. This entails exploring how humor emerges as a resource for participants in situ, rather than looking for instances of humor for categorization without context. Through a detailed analysis of data, we illustrated how humor, indeed, acted as such a resource. Humor was used in building identification, affiliation, mutual relationships and cohesion among the participants. It was also employed as a resource for facework and impression management among pupils engaging with their own familiar class and teachers but also with unfamiliar adult researchers. It was also found to be used in the legitimation of the design ideas and contributing to negotiations of competence and division of labor in an uncertain situation, as the pupils faced a design and Making project for the first time, in a way balancing between "being serious" and "arseing around".

\section{ACKNOWLEDGEMENTS}

This study was funded by Academy of Finland (Grant \#324685, Make-a-Difference project) and by European Union's Horizon 2020 Research and Innovation programme (Grant \#787476, COMnPLAY SCIENCE project. This research is connected to the GenZ-project, a strategic profiling project in human sciences at the University of Oulu, supported by the Academy of Finland (Grant \#318930) and the University of Oulu. 


\section{REFERENCES}

[1] T. Almeida, R. Comber, G. Wood, D. Saraf and M. Balaam. 2016. On Looking at the Vagina through Labella. In Proceedings of the 2016 CHI Conference on Human Factors in Computing Systems, 1810-1821.

[2] B. Bell. 2019. You take fifty photos, delete forty nine and use one": A qualitative study of adolescent imagesharing practices on social media. International Journal of Child-Computer Interaction, 20, 64-71.

[3] M. Bucholtz and K. Hall. 2005. Identity and interaction: A sociocultural linguistic approach. Discourse Studies, 7, 4-5, 585-614. DOI:10.1177/1461445605054407

[4] B. Çelik and K. Gündoğdu. 2016. The effect of using humor and concept cartoons in high school ICT lesson on students' achievement, retention, attitude and anxiety. Computers \& Education, 103, 144-157.

[5] A. Chandrasekaran, A. Vijayakumar, S. Antol, M. Bansal, D. Batra, C. Lawrence Zitnick and D. Parikh. 2016. We are humor beings: Understanding and predicting visual humor. In Proceedings of the IEEE Conference on Computer Vision and Pattern Recognition, 4603-4612.

[6] B. Davies and R. Harré. 1990. Positioning: The discursive production of selves. Journal for the Theory of Social Behaviour, 20, 1, 43-63. DOI:10.1111/jtsb.1990.20.issue-1

[7] J. Denner, S. Bean, and L. Werner. 2005. Girls Creating Games: Challenging Existing Assumptions about Game Content. In Proceedings of DiGRA 2005: Changing Views: Worlds in Play, International Conference.

[8] S. Dewar, S. Islam, E. Resor, and N. Salehi. 2019. Finsta: Creating "Fake" Spaces for Authentic Performance. In Extended Abstracts of the 2019 CHI Conference on Human Factors in Computing Systems.

[9] C. Dormann and M. Neuvians. 2012. Humor patterns: teasing, fun and mirth. In Proceedings of the First Workshop on Design Patterns in Games.

[10] D. Fitton, J. Read and M. Horton. 2013. The challenge of working with teens as participants in interaction design. In Extended Abstracts of the 2013 CHI Conference on Human Factors in Computing Systems, 205-210.

[11] N. Foldager, H. Hansen, M. Tewes and T. Bjørner. 2016. Designing an Engaging and Informative Application About First Aid: Gamification and Humor as Design Elements in a Serious Game. In International Conference on Smart Objects and Technologies for Social Good, 78-87.

[12] R. Gardner. 2008. Conversation analysis and orientation to learning. Journal of Applied Linguistics, 5, 3, 229244. doi: 10.1558/japl.v5i2.229
[13] P. Glenn and E. Holt. 2013. Introduction. In Studies of laughter in interaction, P. Glenn and E. Holt (eds.). Bloomsbury, London, 1-22.

[14] E. Goffman. 1956. The presentation of self in everyday life. University of Edinburgh Press, Edinburgh.

[15] E. Goffman. 1971. Relations in public: Microstudies of the public order. Basic Books. New York.

[16] E. Goffman. 1983. The interaction order: American Sociological Association, 1982 Presidential Address. American Sociological Review, 48, 1, 1-17. DOI: $10.2307 / 2095141$

[17] S. Goldman and M. Bullock. 2013. Comic Creation, Comic Relief: kids expression of self and others. In Proceedings of the 12th International Conference on Interaction Design and Children, 447-450.

[18] D. Grammenos. 2008. Game over: learning by dying. In Proceedings of the 2008 CHI Conference on Human Factors in Computing Systems, 1443-1452.

[19] D. Grammenos and M. Antona. 2018. Future designers: Introducing creativity, design thinking \& design to children. International Journal of Child-Computer Interaction, 16, 16-24.

[20] M. Haakana. 2001. Laughter as a patient's resource: Dealing with delicate aspects of medical interaction. Text, 21, 187-219.

[21] M. Handel and J. Herbsleb. 2002. What is chat doing in the workplace?. In Proceedings of the 2002 ACM conference on Computer supported cooperative work, $1-10$.

[22] G. Hatcher, W. Ion, R. MacLachlan, A. Wodehouse, M. Sheridan and B. Simpson. 2016. Humour processes for creative engineering design. In 14th International Design Conference, 1015-1024.

[23] G. Hatcher, W. Ion, R. Maclachlan, A. Wodehouse, B. Simpson and M. Marlow. 2019. Applied Humor in Creative Product Design. In Creativity and Humor, 157182.

[24] M. Haugh and D. Bousfield. 2012. Mock impoliteness, jocular mockery and jocular abuse in Australian and British English. Journal of Pragmatics, 44, 1099-1114.

[25] K. Helms and Y. Fernaeus. 2018. Humor in design fiction to suspend disbelief and belief. In Proceedings of the 10th Nordic Conference on Human-Computer Interaction, 801-818.

[26] G. Hendry, S. Wiggins and T. Anderson. 2015. "That's me being stupid": Using discursive psychology to analyse self-deprecating humour as a means of constructing group cohesion in PBL In Global Research Community: Collaboration and Developments. International research symposium on PBL, E. de Graaff, A. Guerra, A. Kolmos and N. A. Arexolaleiba (eds.). Aalborg University Press, Aalborg, 70-82. 
[27] E. Holt. 2013. "There's many a true word said in jest": Seriousness and nonseriousness in interaction. In Studies of laughter in interaction, P. Glenn and E. Holt (eds.), Bloomsbury, London, 69-90).

[28] N. Iivari and M. Kinnula. 2018. Empowering children through design and making: towards protagonist role adoption. In Proceedings of the 15th Participatory Design Conference: Full Papers-Volume 1.

[29] O.S. Iversen, R.C. Smith and C. Dindler. 2018. From computational thinking to computational empowerment: a 21 st century PD agenda. In Proceedings of the 15th Participatory Design Conference: Full Papers-Volume 1.

[30] R. Jones. 2005. Sites of engagement as sites of attention: Time, space and culture in electronic discourse. In Discourse in action: Introducing mediated discourse analysis, S. Norris and R. H. Jones (eds.). Routledge, London, 141-154.

[31] O. Kallio and M. Masoodian. 2019. Featuring Comedy through Ludonarrative Elements of Video Games. Entertainment Computing.

[32] P. Khooshabeh, C. McCall, S. Gandhe, J. Gratch and J. Blascovich. 2011. Does it matter if a computer jokes. In Extended Abstracts of the 2011 CHI Conference on Human Factors in Computing Systems, 77-86.

[33] B. Kim and W. Ho. 2018. Emergent social practices of Singapore students: The role of laughter and humour in educational gameplay. International Journal of ChildComputer Interaction, 16, 85-99.

[34] M. Kinnula, N. Iivari and T. Ijäs. 2012). On the brink of adulthood: a qualitative study of adolescent engagement with the internet. In Proceedings of the 7th Nordic Conference on Human-Computer Interaction: Making Sense Through Design, 418-427.

[35] S. Krusche, D. Dzvonyar, H. Xu, and B. Bruegge. 2018. Software Theater-Teaching Demo-Oriented Prototyping. ACM Transactions on Computing Education, 18, 2, 10.

[36] B. Kudrowitz. 2010. Haha and aha!: Creativity, idea generation, improvisational humor, and product design. Ph.D Dissertation. MIT, Cambridge, MA.

[37] P. Kulms, S. Kopp and N. Krämer. 2014. Let's be serious and have a laugh: Can humor support cooperation with a virtual agent?. In International Conference on Intelligent Virtual Agents, 250-259.

[38] C. Kynigos and N. Yiannoutsou. 2018. Children challenging the design of half-baked games: Expressing values through the process of game modding. International Journal of Child-Computer Interaction, 17, 16-27.

[39] M. Leijon. 2016. Space as designs for and in learning: Investigating the interplay between space, interaction and learning sequences in higher education. Visual
Communication, 15, 1, 93-124.

DOI:10.1177/1470357215608553

[40] R. Martin, P. Puhlik-Doris, G. Larsen, J. Gray and K. Weir. 2003. Individual differences in uses of humor and their relation to psychological well-being: Development of the Humor Styles Questionnaire. Journal of research in personality, 37, 1, 48-75.

[41] R. Martínez, L. Durán and M. Hikida. 2017. Becoming "Spanish Learners": Identity and Interaction Among Multilingual Children in a Spanish-English Dual Language Classroom. International Multilingual Research Journal, 11, 3, 167-183. DOI:10.1080/19313152.2017.1330065

[42] I. Menne, B. Lange and D. Unz. 2018. My Humorous Robot: Effects of a Robot Telling Jokes on Perceived Intelligence and Liking. In Companion of the 2018 ACM/IEEE International Conference on Human-Robot Interaction, 193-194.

[43] J. Meyer. 2000. Humor as a double-edged sword: Four functions of humor in communication. Communication theory, 10, 3, 310-331.

[44] C. Mills and A. Carwile. 2009. The good, the bad, and the borderline: Separating teasing from bullying. Communication Education, 58, 2, 276-301. DOI:10.5172/hesr.2010.19.4.505

[45] NCBE. (2016). National core curriculum for basic education 2014. Finnish National Board of Education. Helsinki.

[46] K. Nishida. 1958. Intelligibility and the philosophy of nothingness. Maruzen, Tokyo.

[47] S. Norris. 2004. Analyzing multimodal interaction: A methodological framework. Routledge, London.

[48] S. Norris. 2011. Identity in (inter)action: Introducing multimodal (inter)action analysis. De Gruyter Mouton, Berlin.

[49] T. Oittinen. 2018. Multimodal accomplishment of alignment and affiliation in the local space of distant meetings. Culture and Organization, 24, 1, 31-53. https://doi.org/10.1080/14759551.2107.1386189

[50] J. Pater, Y. Nadji, E. Mynatt and A. Bruckman. 2014. Just awful enough: the functional dysfunction of the something awful forums. In Proceedings of the 2014 CHI Conference on Human Factors in Computing Systems, 2407-2410.

[51] A. Pomerantz. 1984. Agreeing and disagreeing with assessments: Some features of preferred/dispreferred turn shapes. In Structures of social action: Studies in conversation analysis, M. J. Atkinson and J. Heritage (eds.). Cambridge University Press, Cambridge, 57-101.

[52] J. Read, D. Fitton, B. Cowan, R. Beale, Y. Guo and M. Horton. 2011. Understanding and designing cool technologies for teenagers. In Extended Abstracts of the 
2011 CHI Conference on Human Factors in Computing Systems, 1567-1572.

[53] D. Rowland, K. Appiah-Kubi, V. Shipp, R. Mortier and S. Benford. 2015. Annotation and anonymity: playful photo-sharing by visiting groups of teenagers. In Proceedings of the 12th International Conference on Advances in Computer Entertainment Technology.

[54] R. Scollon and S. Scollon. 2004. Nexus analysis: Discourse and the emerging Internet. Routledge, London.

[55] S. Scollon and I. de Saint-Georges. 2012. Mediated discourse analysis. In The Routledge Handbook of Discourse Analysis, J. P. Gee and M. Handford (eds.). Routledge, London, 66-78.

[56] N. Sonalkar, A. Mabogunje, L. Leifer and B. Roth. 2016. Visualising professional vision interactions in design reviews. CoDesign, 12, 1-2, 73-92.

[57] F. Søbstad and O. Lillemyr. 2010. Humour and selfconcept: A multicultural perspective. International Research in Early Childhood Education, 1, 1, 71-83.

[58] D. Søndergaard. 2018. The thrill of bullying. Bullying, humour and the making of community. Journal for the Theory of Social Behaviour, 48, 1, 48-65.

DOI:10.1111/jtsb.12153
[59] B. Tay, S. Low, K. Ko and T. Park. 2016. Types of humor that robots can play. Computers in Human Behavior, 60, 19-28.

[60] A. Wee. 2019. Space and Identity Construction: A Study of Female Singaporean Undergraduates in the UK. Journal of International Students, 9, 2, 384-411. DOI:10.32674/jis.v9i2.643

[61] M. Wen, N. Baym, O. Tamuz, J. Teevan, S. Dumais and A. Kalai. 2015. OMG UR Funny! Computer-Aided Humor with an Application to Chat. In Proceedings of the Sixth International Conference on Computer Creativity, 86-93.

[62] T. Wright, E. Boria and P. Breidenbach. 2002. Creative player actions in FPS online video games: Playing Counter-Strike. Game Studies, 2, 2.

[63] Y. Yu and N. Tek-Jin. 2017. Products with a sense of humor: Case study of humorous products with giggle popper. International Journal of Design, 11, 1.

[64] D. Zhang, W. Song, X. Liu, L. Liu and X. Zhao. 2018. Research on Humor Recognition. In 2018 IEEE 9th International Conference on Software Engineering and Service Science, 152-155. 